\title{
Article
}

\section{A Tool for Better Land Management}

\author{
Bernardo Carvalhinho ${ }^{1}$, Rodrigo Rocha Silva ${ }^{2,3}$ and Jorge Bernardino ${ }^{1,3, *(D)}$ \\ 1 Polytechnic of Coimbra-Coimbra Institute of Engineering (ISEC), 3030-190 Coimbra, Portugal; \\ a21270434@isec.pt \\ 2 FATEC Mogi das Cruzes, São Paulo Technological College, Mogi das Cruzes 08773-600, Brazil; \\ rrochas@dei.uc.pt \\ 3 Centre of Informatics and Systems of University of Coimbra (CISUC), 3030-290 Coimbra, Portugal \\ * Correspondence: jorge@isec.pt
}

Received: 5 October 2020; Accepted: 24 November 2020; Published: 27 November 2020

\begin{abstract}
The ability of keeping a record of geospatial information, knowing how it changed over time, is crucial for landscape analysis and territorial government. Land management is still a problem. Many governmental databases are incomplete, and there is a lack of reliable information. Good land management implies having a tool that can keep track of all the information available about a certain property and its changes over time. In this paper, we propose a land management tool where managers access all the information on a certain parcel of land-its boundaries, the land registration, a map which verifies the landcover, and the historic of updates of territorial limits. With the proposed tool, it is possible to edit the information of any property, whether it is active or not-that is, to also edit properties that no longer exist today, but that the user wants to add information to, for legal or other reasons. Keeping track of data properties' revision history is groundbreaking due to the fact it is not well developed in existing tools. We will look at Brazil as a use case, where land management is a critical problem.
\end{abstract}

Keywords: spatial data; property history; temporal GIS; GIS property registration system; GIS historical land management

\section{Introduction}

The information technology facilitates the development of land use systems based on the simulation of dynamic land use interactive processes [1]. There is also an increasing use of geoinformatics in the design of geoinformation systems and decision support systems for realizing sustainable land management at different scales and for specific user groups (land registry specialist, land analyst, and field inspector). A digital geoinformation infrastructure and policy framework is emerging for this purpose at global, regional, national, and local levels, as stated by Beek [2].

Consequently, land management is essential for governments and companies for keeping control of updated historical information [3]. The control of all transactions in which a property may be involved, regularization of irregular settlements and the titling of its occupants are some relevant examples. The problem is that many governmental databases are incomplete and do not contain reliable information. In addition, many of the databases do not follow the evolution of properties over time, keeping track of the data revision history and that does not allow the edition of historical spatial data.

As an example of this poor management, we used the use case of Brazil, where this problem is grave. The landowners spend a lot of time and money on registering and licensing as required by law. Normally a pile of papers and a large stack of information are required for each property. Consequently, landowners and municipal managers need a better way to make the system work to effectively manage the land. 
In Brazil, there is still the problem of false documentation. This occurs due to the deficiencies found in the land control system, where, despite the various proposals, the government has not yet implemented a single land registry or at least a specific register for large properties. There is also no articulation and cross-checking of data between land agencies at the three levels of government (federal, state, and municipal). Furthermore, there are "paper lands", i.e., properties that exist only in paper, and false documentation properties size is bigger than the dimension of the Amazon itself [4].

Land grabbing has become a priority topic in academic research, and a political concern, due to interests in the dynamics of the phenomenon and its negative impact on the sustainable development of agriculture in rural areas [5]. Land grabbing is usually associated with other crimes [6]. The use of gunmen to evict former owners and/or protect themselves from possible invaders is quite common, as is the use of land for illegal extraction and criminal practices. There are families that have the right to a certain land given by the Federal Constitution, but they continue to be exposed to the public policy on Agrarian Reform, and the Federal Justice sentences to be carried out by public authorities. This case of illegal possession by squatters is an additional issue in the history of conflicts that has been going on for more than 15 years in the Mato Grosso region.

The invasions are still a problem that persists today, causing losses. In Brazil there is a very large amount of land that is invaded, and landowning companies need to carry out periodic inspections to prevent invasions. The Brazilian courts determine that it is the obligation of the companies to carry out such inspection. When a property with constructions is invaded, the process of building and managing the losses is suspended until there is a court decision that guarantees the repossession of the property, which can take weeks or months. For construction companies, the invasions involve more expenses. These invasions also occur due to situations of poverty [7], where families that do not have places to live invade public land, building inadequate housing in order to exercise its minimum housing condition, with serious risks to sanitation, health, and safety.

There is a study carried out in [8] that shows the mismanagement over the years of the land used for the creation of dams and hydroelectric plants along the Tocantins River. The consequences caused by dams are the most diverse, involving social and environmental cases, geophysical and hydrological risks. Many of the dams built in Brazil did not consider relevant aspects, such as deforestation and land expropriations. They were built in regions of native closed forests, many of them flooded areas of fertile and agricultural land. Additionally, they caused the indigenous people to leave their homes and lands because of the floods caused by dams. They were impacted by these constructions and some promises those companies made them, which have never been fulfilled [9]. The use of our tool makes possible to assist in this management by keeping everything in a complete database and with information about all properties within any period.

Another type of transaction that exists in the real estate world is expropriation, which is one of the most serious resolutions used by governments to intervene in property law. In this case, the state takes a certain good in a compulsory way for reasons of public interest (utility, public need or social interest), causing its owner to lose the right to property, but normally paying fair compensation.

Brazil is taken as a case study in this paper, but many other countries have similar problems of land management [10-14]. The real estate world is full of problems and governments need help to maintain all this material in a place where they can check all the information that a certain property has all its history. Governments and companies need tools that help with the land management, as presented in [15]. If governments pay attention to this aspect, it will be possible to avoid certain situations where there is land that is not properly documented. There is unlawful occupation of land [16-20] in many countries, such as South Africa, in which supposed owners take advantage of false documents, with the appearance of being truthful, to seize public land or speculate for obtaining illicit advantages.

Therefore, land management tools are not only geographic information systems as they represent a legal lawfully meaningful relationship amongst people and between people and land. As the land management activity on the one hand deals with huge amounts of data, which moreover are of a 
very dynamic in nature, and on the other hand requires a continuous maintenance process, the role of information technology is of strategic importance [21].

In this work, we propose a tool that allows the edition of properties' spatial data history, which it is not well developed in existing tools. What is meant by property data history is how the property has evolved over the years, since it was created and preserved all the modifications. Therefore, we can have always in the database the details of all properties in any period, so that users can consult and/or update this information.

We present a new characteristic for property history-that is, the possibility of the edition of the spatial data history, something that is not provided in the tools for better land management. The data history edition is an important feature that enables governmental databases with all the historical information about a certain property. In some cases, we have properties with incorrect data, such as the property registration year. However, it is not be possible to alter such important information, because today's databases do not allow the user edit properties' history. For example, we have a property that existed in the year 2012 and, in that year, it suffered an invasion that was not reported. If we want to report that invasion today it is not possible, because current tools do not allow the user to manage historical data. Nevertheless, this control of properties history is groundbreaking since it improves the precision and reliability of the database.

Therefore, this work aims to build an application that offers the possibility to consolidate and integrate a property database with environmental and cartographic data, using a Geographic Information System (GIS) platform [22]. We use QGIS, which is a free and open source cross-platform desktop geographic information system that supports viewing, editing, and analysis of geospatial data [6]. The objective of this work is to optimize real estate management and facilitate access to integrated data for the execution of inspection, invasion, complaints, and management of legal processes involving properties. In this way, the main objective is to solve the problems of land management, which is an evolving area and needs monitoring using digital technology. The system was developed in the MVC architectural pattern using Python with the leaflet framework and QGIS. To the best of our knowledge, there is no other methodology which allows the edition of historical geospatial information.

The remainder of this paper is organized as follows. In Section 2, we discuss related work on land management. Section 3 describes the methodology used in this work, such as the data model, the proposal for land history management problem, and an explanation about the Web application. Section 4 reports the results of the land history and some examples from the Web application and Section 5 discusses these results. Finally, Section 6 presents the conclusions and some ideas for future work.

\section{Related Work}

Practical tools which can help local users and multi-disciplinary teams work together on the land management problem at the local to regional levels have emerged only very recently. In this section, we present a summary of papers that focus on the land management problem and how to solve this problem.

Hans Hurni [23] review existing approaches for planning integrated land management vis à vis the requirements set forth by the concept of sustainable land management as it emerged from the UNCED process since the Rio conference in 1992, and propose appropriate conceptual and methodological tools in response to these requirements. The author advocates that assessment tools will require transdisciplinary methods that involve natural, social, and political sciences as well as local knowledge systems. Additionally, according to Pieri [24], there is a need to move from concepts and prescriptive approaches to an integrated approach to the physical planning and the social and institutional dimensions of land management. A specific approach has been developed for this purpose, which is called "sustainable development appraisal" (SDA). However, SDA is only a methodological tool for the participatory assessment of sustainability from local to regional planning levels [25]. 
The authors Laskos, Cazella, and May Rebollar [26] denote that Brazilian rural spaces play an important role in the management of environmental and social issues. Brazil has a property registration system, but it is out of date and most of the information provided is not verified. This system also leads to various frauds associated with tax payments, changes in ownership, etc. They suggest the construction of a solid database to support management institutions and notaries so that it is possible to carry out studies overtime on these same properties. Additionally, Thomson and Simpson's research [27] aims to investigate the role of historical farm management decisions in controlling the utilization of grazing resources by domestic livestock under variable environmental conditions, and the impact that these decisions have upon early farm viability and land degradation, using environmental simulation modelling. The focus for these investigations is Iceland, as an example of a place where the contemporary landscape has been extensively modified by grazing in the past. However, these works only use simulation tools.

Victorino, Amorim, and Shimabukuro [28] present the development of a WebSIG using PostgreSQL in combination with PostGIS. This application allows the land registry to obtain information of interest like consult the information about the owner, among other features. This paper also presents the relationship entity diagram, to facilitate the understanding of the application's behavior. This application aims to maintain a reliable and updated register helping in decision-making, planning, and municipal management. Although this work aims to present the main aspects involved in the development of a system that helps information sharing between the territorial land registry and property registry systems in small- and medium-sized municipalities, it does not deal with spatial historical data.

The authors in [29] discuss the importance of updating cadastral data, without losing the historical data of the cadastral databases for town planning activity. They also present an experiment, showing examples of using the database and the gvSIG tool, where through map visualization it is possible to analyze the differences from the past to the present, but it does not allow changing any information of the past data, as proposed in this work. The authors emphasize the lack of methods, viable in terms of costs and benefit, mainly those that make possible the maintenance of data history that has hindered significantly the planning activity, considering the importance of historical studies for understanding certain facts that may point to future occurrences, which our work intends to solve.

Francisco and Imai [30] mention the fact that there are still few works that discuss the representation of information space, particularly regarding the changes that occurred in the urban area. For this, they present an approach for the representation of the time-space of the land registry data used by City Halls. This approach consists of maintaining the modifications, by overlapping and adding to the object through versioning (storing the previous version) and this new version of the object is a new instance that contains the inherited properties. Nevertheless, the proposal does not implement interfaces that facilitate the use of applications for maintaining the geographic database, in order to facilitate its use by users in daily operations.

Toledo and Bertotti [31] present the development of a land management system (SIGEF) to improve the land structure in Brazil. For this operation, the data entry is made from a spreadsheet, which was duly prepared to carry out all the formatting rules required by SIGEF. This spreadsheet is sent to SIGEF, where the server checks for errors. If the process is approved, the certification of the property is immediate. The property map and the descriptive memory are created from the system itself, automatically. The certification is subject to validation by the Real Estate Registry Office, thus ending the process of certification of rural properties. The proposed system was at an early stage, still with no practical results.

Freitas and Lima [32] demonstrate the importance of GIS tools in the process of preparing descriptive plans of the plots for the purpose of land tenure regularization in a community classified as ZEIS (Space Areas of Social Interest) in Fortaleza, Brazil. The use of this tool allows obtaining a better precision in the location of the parcels in the territory of the city, the mapping of accumulated information, permitting a greater level of understanding the information contained in the database. 
The main contribution of this work was the introduction of spatial data in the database that contains the cadastral socioeconomic information in order to support the ZEIS planning process.

In [33], the authors present the case of Paraiba state, more specifically the municipality of Monteiro, which does not have a reliable rural registry, which occurs many times in Brazil. For this project, they use the ArcGIS tool and present the SHAPE attributes of Titled Lots. The filling of these lots was based on technical materials that they obtained. Then they used an ESRI JavaScript API, so the data could be viewed online without the need for specific software for visualization. This tool allows for a faster dissemination of information, managing technical materials more effectively, and developing a thematic map showing data properties before the certification process.

Based on complete use of mature spatial information technologies and on land use and management, Liang et al. [5] developed the Dingzhuang town information system of land resources management based on spatial data. It provides land use and management with real-time information and performs functions like property search map, map search function, visual inquiry of land information and dynamic spatial graphic data. The basic functions of this system include land use planning, basic farmland management, the management of land for construction use, land survey, land registration and so on. Besides, it realizes the basic land management of each patch in the village and town level, as well as property search map and map search function.

Mondal et al. [21] present a study that develops a case study of land information system using cadastral techniques of Tirat and Chalbalpur rural region of Raniganj in Barddhaman district of India, which contains cadastral information. The final goal was to generate digital maps which will facilitate land management and planning and in particular land registration and the issuance of land titles in order to promote security of land tenure and reduce land disputes, such is the use case of Brazil, used in our work.

Recently, Mishra et al. [34] published a study based on remote sensing (RS) and geographic information system (GIS) techniques, to monitor the changes in land use and land cover patterns of Rani Khola watershed of Sikkim Himalaya for the periods 1988-1996, 1996-2008 and 2008-2017. The result of this study reveals that the major land use in the watershed is forestry. Due to massive afforestation program, declaration of Sikkim as organic state (2005), stringent law enforcement in forestry sector and sustainable agroforestry systems the area under dense forest has increased by $16.4 \%$ between 1988 and 2017. This study utilizes the RS and GIS approach which is one of the most prominent technology at present for spatio-temporal analysis. That is possible through other conventional mapping techniques. The analysis and findings of the study have important policy implications for the sustainable land-use/cover practices in the Sikkim Himalaya.

Many of the aforementioned papers present an approach to poor land management, through the use of GIS, to assist and improve the way in which information will be used and stored. However, a few propose solutions for maintaining the property data history. Our work has these two objectives combined, proposing a new approach to properties spatial data history manipulation using QGIS with a Web application.

\section{Methodology and Tools}

This section describes the methodology and the tools used for the creation of the Web application, the database, and the proposal to deal with property data history. The creation of this Web application was done using Python and Flask, a small web framework written in Python and based on the WSGI Werkzeug library and the Jinja2 library. Flask has the flexibility of the Python programming language and provides a simple model for web development). In order to view the properties on the Web, Leaflet [35] was used, that is a JavaScript library specialized in visualizing geographic data on the Web.

The database used for the application was PostgreSQL since the QGIS already has an extension for this database. We also describe how the property history method works, and the lack of existing proposals on the market to deal with this problem. 
In Figure 1 we can see the architecture of the tool. The Web application follows a normal Model-View-Controller (MVC) structure. In the model, we can see some of the most important classes of the Web application: Property, Beneficiary, etc. The model communicates with PostgreSQL to access the data and each task done by the user is saved in the database. The PostgreSQL database also communicates with QGIS, where we can see the representation of the data in a more informal way. All the actions that the user performs in QGIS are also saved in the database. The communication between the Web application and QGIS is via the database, because when a property is created in QGIS and we want to visualize in the web application, first we have to save it in the database and then access the web application that extracts the property data from the database.

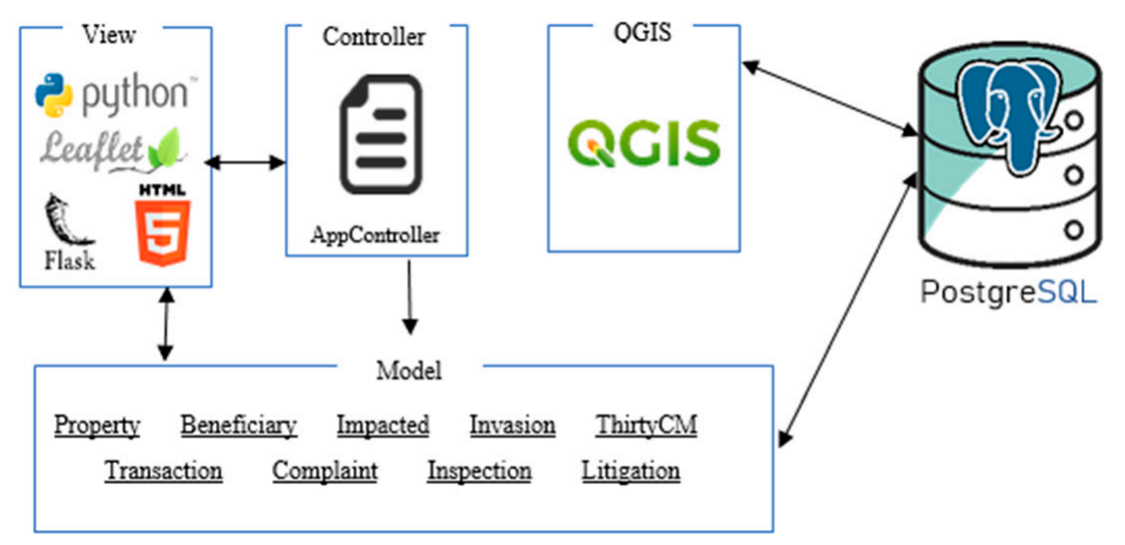

Figure 1. Tool Architecture diagram.

\subsection{Property History in Software Tools}

One of the problems that this work intends to solve is the edition of properties' historical data. The history of a property over time consists of knowing how it has evolved over the years since creation and maintaining the respective details of the modifications. In addition to being able to maintain the historical data of the properties, it should also be possible to edit this history, that is, it should be viable to edit a property that no longer exists today, but that the user wants to add some information for example property registry date.

QGIS is a free and open source Geographic Information System (GIS) application that was used to achieve the proposal for the property history problem. We use QGIS because is one of the best tools for dealing with geographic data, as described in [36]. One of our goals was to find one solution for the property history problem using a tool as good as the commercial ones in the market (e.g., ArcGIS [37]) but without acquisition costs. ArcGIS is a GIS for working with maps and geographic information maintained by the Environmental Systems Research Institute (ESRI). It is used for creating and using maps, compiling geographic data, analyzing mapped information, sharing and discovering geographic information, using maps and geographic information in a range of applications, and managing geographic information in a database. Other platforms were tested, such as gvSIG [38] and Google Earth Pro [39] but they do not have the core functionalities of dividing and joining properties.

QGIS was the best tool since it offers the divide and join functionalities under a simple and intuitive design. However, this platform did not have the ability to deal directly with the property historical data. Then, to solve this problem, we propose a method using the existing functionalities. QGIS had already the functionalities to divide and join properties, but when we edit a property QGIS does not save the previous version, it is always portraying the same version. Therefore, by using the copy function given by QGIS we have a solution for saving historical property data.

The method for property history edition consists of the following: we have a property in the database that we are going to edit, but we want to keep all the information of this property. In the QGIS tool, we select the property and create a copy, which will be automatically added to the database. In order to keep the history, we will make our changes to the copy which, after being edited, will be the 
most recent version of the property. If we want to make a division, we use a functionality offered by QGIS that allows making cuts in the property. These cuts will give rise to new properties that have their data equal to the property that originated them. If we want to make a join, we must select properties that have intersecting parts (vertices or edges). The join is made through a functionality offered by QGIS. The same happens with the division, the parameters must then be edited. By following these steps, it is possible to maintain the property historical data over time without losing information.

Through this method, we can maintain the history of a property over time. For distinguishing these properties, the parent-child attributes, such as the creation date, will be used, or an attribute that indicates which one is the parent property of the respective selected property.

Nevertheless, the property history problem persists in the Web application. The divide and join functionalities must be executed within QGIS since these two functions deal with editing the design of the property. But all other actions involving the property must be kept in the database keeping the history of the property. When we have a property and we want to associate a complaint (or other action such as an invasion, beneficiary, impacted, inspection or litigation or make another transaction, such as a purchase, sale, transfer, expropriation, purchase of installment, easement, regularization) about that referred property, we have to follow the same idea described previously. We create a copy of the property and this copy will have the same data as the previous property, but with the complaint associated with this copy. In the Web application, users do not need to make a copy, because this action will be done automatically by the application. With that, the user will know when the property had the complaint and when it did not. The reasoning is the same as the division and join of properties. We will always have the property history, whatever the change made in the property.

This problem was partially solved by ArcGIS, another platform comparable to QGIS, and the most used in this area. ArcGIS presents a solution called Archive [40] where it is possible to store properties in a table as they change over time. The problem with this solution is that it does not allow older properties to be edited. That is, if in the future we want to associate a document with a property that no longer exists, it is not possible to do so. Actually, ArcGIS is the only tool that manages the objective of the real estate history, despite not being completely efficient. The proposed solution allows us to do what ArcGIS does, but with the possibility to edit older versions of the properties to achieve a consistent database.

The proposed tool is more complete than that of ArcGIS due to the fact that we can edit older properties and associate any type of information with them and not just the most recent properties, those that currently exist. Thus, it is possible to create a complete and reliable database.

\subsection{Web Database}

In this section, we describe the database that is used in the Web application. Figure 2 illustrates the entity-relationship model (or ER model). For readability reasons, this figure only shows the names of tables but not its contents.

The most important tables for the operation of the application are the following:

- Beneficiary: This table represents each possible beneficiary in each transaction of a property. Each beneficiary may have a set of documents registered in the BeneficiaryDocument Table, where each record represents a document.

- Litigation: This table stores each possible record of litigation or pre-litigation; the type of record is identified by a LitigationDegree field. A litigation can be generated from a complaint (Complaint Table), an inspection (Inspection Table) or an invasion (Invasion Table).

- Destination: This table represents each possible transaction for a property. The validity of the registrations is determined by the ReferenceDate attribute. The parameter will be asked, so the user can compare it to the documents and see if the data matches.

- PropertyDocument: This table represents each possible document of each property that is stored. Documents are associated by the registration number, but the system will display to the user, documents with previous or same registration date for the historic transaction of the property. 
- TransactionDocument: This table represents each possible document for each property transaction. This table contains transaction-specific documents that only make sense when the focus is on the details of the transaction. The recent documents that are inherent to the life cycle of the property will be stored in the table PropertyDocument.

- Inspection: This table represents each possible inspection on a property; however, this table will not be used to register an inspection that the main occurrence is an invasion. Invasions are recorded directly in the Invasion Table. Each property can have several inspection records and an inspection can have several actions. Each action of an inspection will be registered in the InspectionAction Table and an inspection can have several documents registered in the InspectionDocument Table and several occurrences registered in InspectionOccurence Table.

- Property: The Property table represents each possible property registration, considering the history. Thus, for each new property or historical transaction a record is created. Each historical transaction of a property will be a row in the property table.

- Impacted: This table represents each possible impact on each transaction of a property. Each impacted person may have a set of documents registered in the ImpactedDocument Table; each record will represent a document.

- Invasion: This table stores each possible claim for a property, where each claim may have a litigation or pre-litigation one (Litigation Table) and the type of record will be given by the LitigationDegree field. For each invasion, the registration of Invaders must take place and will be stored in the Invader Table. The occurrences are also recorded in the InvasionOccurrence Table.

- Complaint: This table stores each possible claim for a property. Each claim may have a litigation or pre-litigation one (Litigation Table), the type of record will be given by the LitigationDegree field and each complaint is in the Complaint Table.

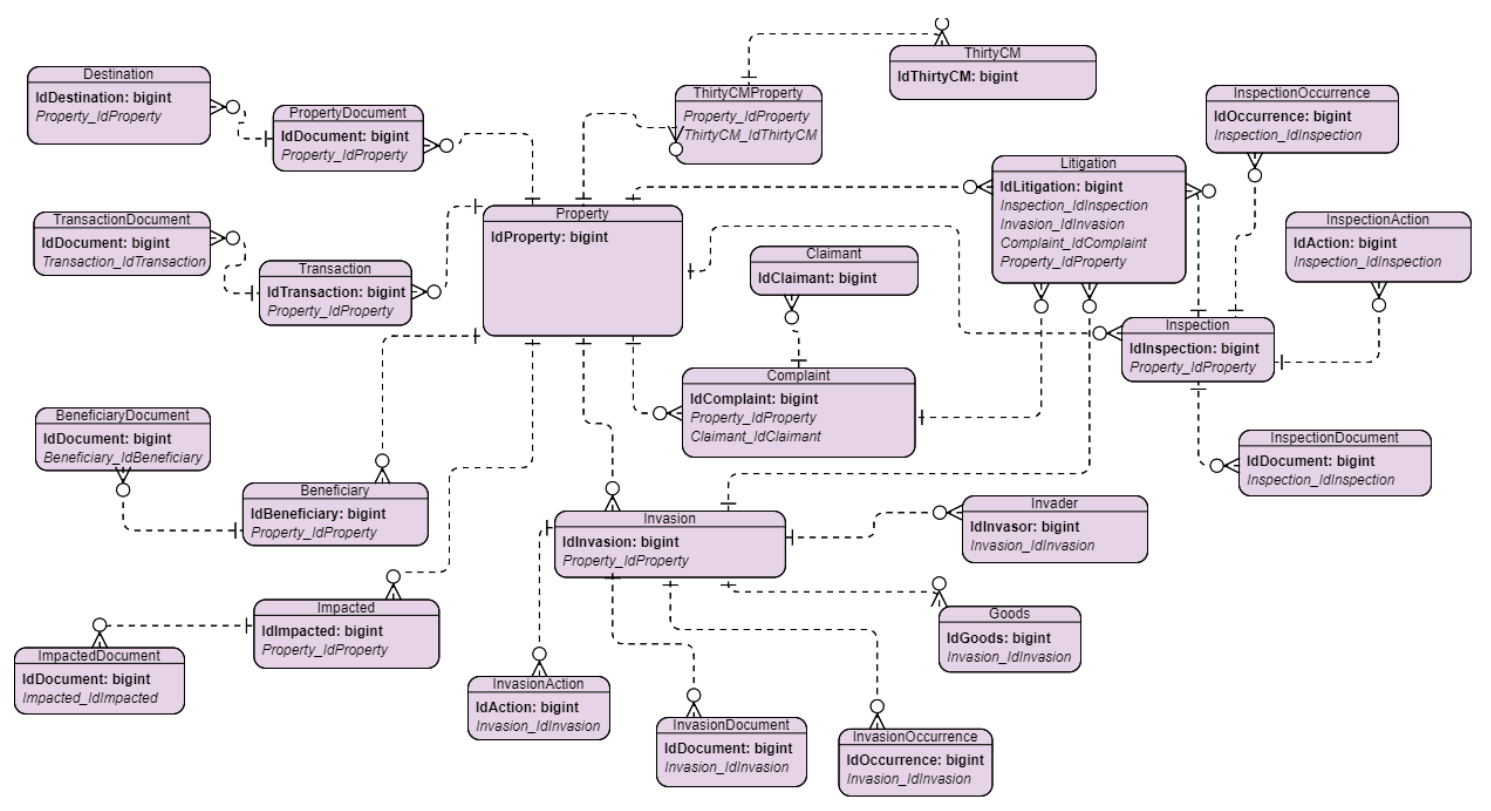

Figure 2. Entity-Relationship Data Model.

\subsection{Web Application}

This section describes how the Web application operates and the communication with QGIS through the PostgreSQL database. The Web application was developed in Python + Flask and Leaflet for viewing properties on the Web. In the application, it is where we optimize real estate management, enabling access to integrated data for the execution of inspection, invasion, complaints, 
and management of legal processes involving real estate. Thus, it is possible to associate the documents with the properties, maintaining a useful land management, with all data stored in the database.

The properties are created in QGIS, which are automatically saved in the database. When we access the application, it is possible to perform various operations, since the completion of the property registration or associate documents to properties (e.g., inspection documents, complaints, invasions and others).

The Web application has the following functionalities:

- Access the properties in the database and visualize them in the Web;

- Complete the registration of a property;

- View the property history, for example, which are the child properties and the parent property;

- Create a Beneficiary, an Impacted, a Destination, a Litigation, a Complaint, an Invasion, a Transaction (expropriation, transfer, purchase, sale, purchase of remaining installment, easement, and regularization) and an Inspection;

- Associate documents to a property;

- Associate documents to a Beneficiary, an Impacted, a Destination, a Litigation, a Complaint, an Invasion, a Transaction, and an Inspection;

- When we create an Invasion, it is also possible to create the Invaders and the Goods involved in the process.

All these actions are performed inside the Web application, which creates a history, i.e., a version of each modification that is applied to a property. The application allows the user to select any property that exists in the database, where this property can be an old version or the most recent version.

When we select and perform an action, for example create a beneficiary, to create the history, we need to create a new version of the property and not update the current version. For this, we create a copy of the property and add it to the database. This duplicated version of a property has a different ID and the origin parameter has the name of the copied property, in order to know who is the father's property. After creating the duplicate, a copy of all property information is added to the duplicate.

The duplication method occurs in the Web application, that creates the duplicate and add it to the database. After adding the duplicate to the database, all the information related to the property (Beneficiary, Impacted, Destination, Litigation, Documents, ThirtyCM, Complaint, Transaction, Invasion, Inspection) is included.

\section{Experimental Results}

This section shows some of the functionalities of the Web application, including examples of land history.

\subsection{Analysis of the History of Properties}

Figure 3 shows an example of the history of a property presented in the database.

In Figure 3 the original property was FozDeArouce (id = 1). Later, this property experienced a division giving rise of two properties: Imovel1 and Imovel2. One of these properties, Imovel2, after some time also suffered a division resulting in two other properties: Imovel3 and Imovel4. Imovel4 go through a division resulting on two other properties: Imovel5 and Imovel6. After, Imovel5 and Imovel6 were merged to form Imovel7, which is also merged with Imovel3 to form Imovel8. Then, Imovel8 is merged with Imovel2 giving rise to Imovel9, that after is divided originating Imovel10 and Imovel11. Finally, Imovel10 suffered another division that gives origin to Imovel12 and Imovel13.

Through the processes of division and union, there exist always an edition of the properties created from the mentioned actions. The reason is because the properties that are created always copy the data of the origin property. Other information must be entered, which distinguishes between the 
parent property from the child property. This copy is mandatory because the QGIS functionalities used for division and union do not allow to reverse these operations.

\begin{tabular}{|r|l|c|c|l|l|l|l|}
\hline id & \multicolumn{1}{|c|}{ name } & date & code & origin & union & division & modified \\
\hline 1 & FozDeArouce & $2018-01-01$ & Foz1234567 & & & Y & Y \\
\hline 6 & Imovel1 & $2018-04-01$ & Foz1234567 & FozDeArouce & Y & & Y \\
\hline 7 & Imovel2 & $2018-04-01$ & Foz1234567 & FozDeArouce & & Y & Y \\
\hline 8 & Imovel3 & $2018-07-01$ & Foz1234567 & Imovel2 & Y & & Y \\
\hline 9 & Imovel4 & $2018-07-01$ & Foz1234567 & Imovel2 & & Y & Y \\
\hline 10 & Imovel5 & $2018-11-01$ & Foz1234567 & Imovel4 & Y & & Y \\
\hline 11 & Imovel6 & $2018-11-01$ & Foz1234567 & Imovel4 & Y & & Y \\
\hline 12 & Imovel7 & $2019-02-01$ & Foz1234567 & Imovel5+Imovel6 & Y & & Y \\
\hline 13 & Imovel8 & $2019-04-01$ & Foz1234567 & Imovel3+Imovel7 & Y & & Y \\
\hline 14 & Imovel9 & $2019-08-01$ & Foz1234567 & Imovel2+Imovel8 & & Y & Y \\
\hline 15 & Imovel10 & $2019-11-01$ & Foz1234567 & Imovel9 & & Y & Y \\
\hline 16 & Imovel11 & $2019-11-01$ & Foz1234567 & Imovel9 & & & \\
\hline 17 & Imovel12 & $2020-02-01$ & Foz1234567 & Imovel10 & & & \\
\hline 18 & Imovel13 & $2020-02-01$ & Foz1234567 & Imovel10 & & & \\
\hline
\end{tabular}

Figure 3. Property history example in QGIS.

\subsection{Analysis of the Web Application}

In this section, we present some examples of the operations that can be done through the Web application.

\subsubsection{Property}

In Figure 4 it is possible to see what is presented in the Web application when selecting a property. 


\section{Property}

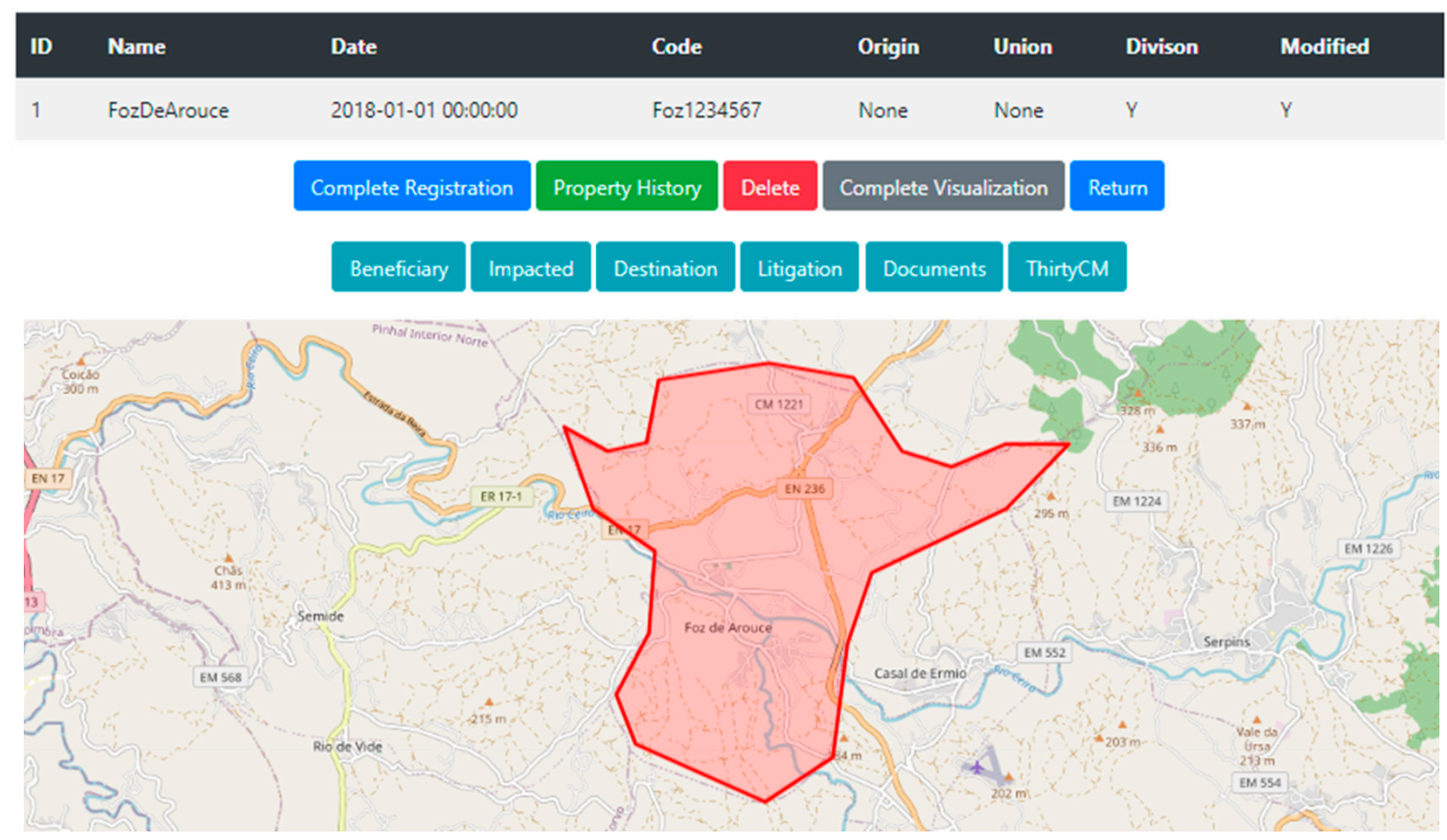

Figure 4. Visualization of a property.

As we can see in Figure 4, the Web application presents a table with the parameters related to property different buttons and a map with the visualization of the property. The buttons have the following functionalities: Complete Registration that allows us to complete the registration of the property; Property History to see the property history in more detail; Delete button that removes the property; Complete Visualization allows us to see all the information related with the property. The Beneficiary, Impacted, Destination, Litigation, Documents, and Thirty CM buttons redirect the user to the respective pages where it is possible to view a table of each one.

\subsubsection{Property History}

Figure 5 below shows the history of a particular property. 


\section{History}

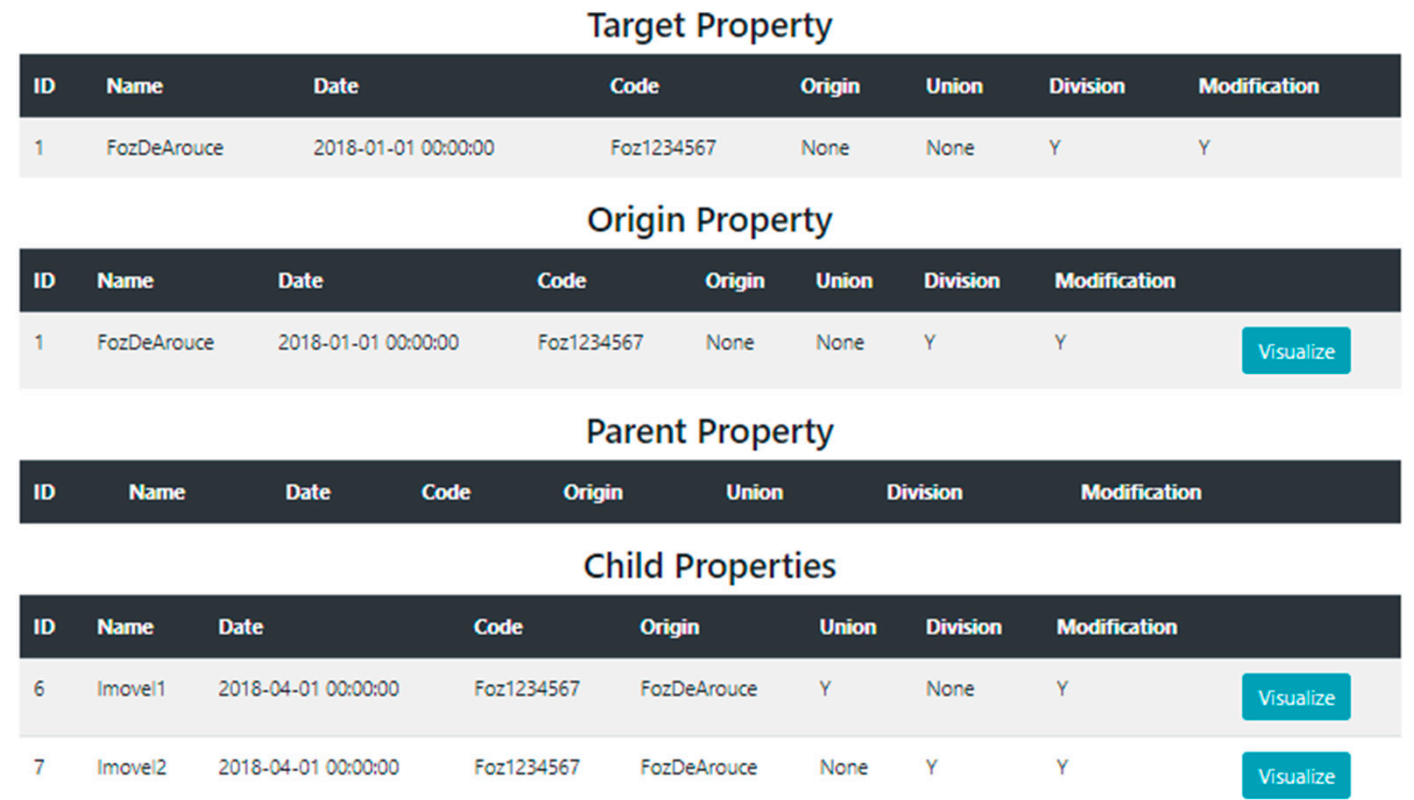

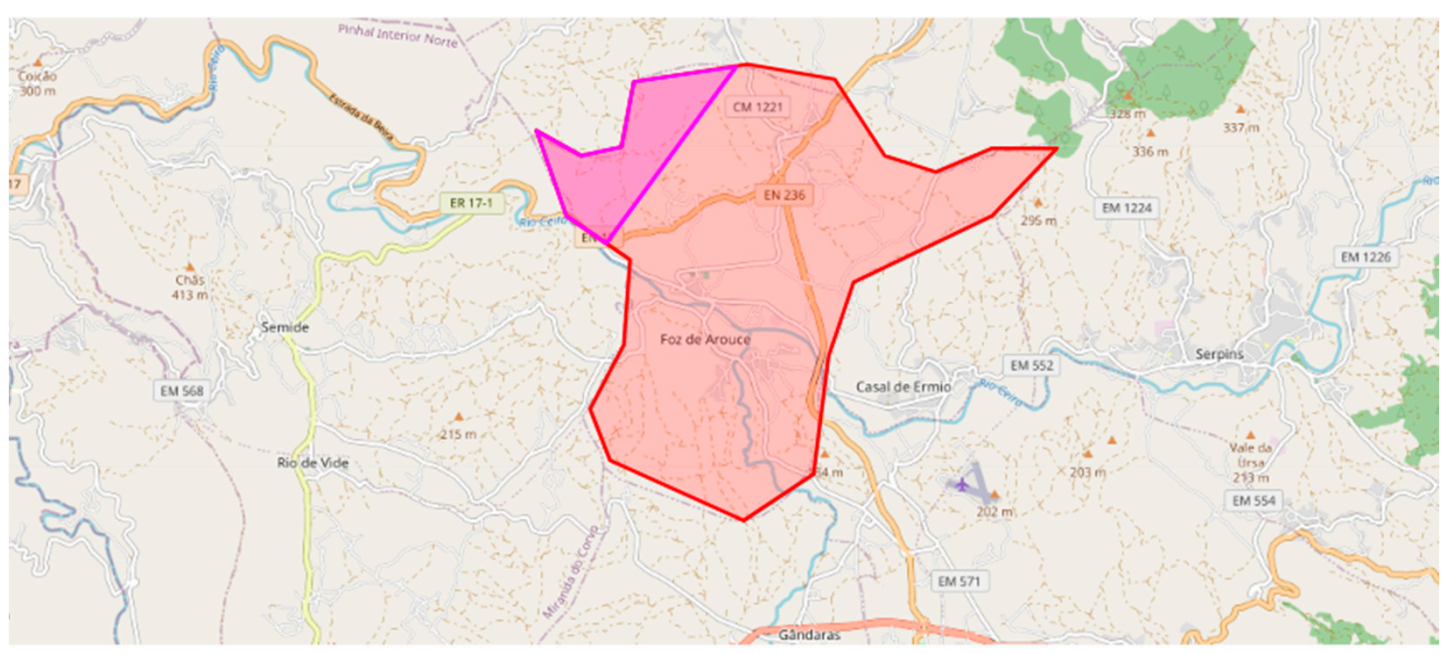

Figure 5. Visualization of the history of a property.

Figure 5 presents four tables: Target, Origin, Parent, and Child. Target shows the selected property, Origin the original property, Parent the property from which derived (parent property) and Child shows what properties it has originated (child property (s)). A map with the selected property is also presented and when we click on the view button it is possible to view the respective property on the same map. In this example, the property in purple is the property called Imovel1. The properties of the same family will have the same Code. If we select a property, in this case "FozDeArouce", we will look at the Origin to see whether the name of the parent is written on it. In this case it did not have a name, so this means this property is the original one. In order to see if this property has originated some children, we look at the properties with the same Code and see if the Origin name in those properties is the same of "FozDeArouce" and, if it is, then we have its children. 


\subsubsection{Beneficiary}

In Figure 6, it is possible to see the process of creating a beneficiary, as well as viewing the respective table of beneficiaries of a given property. Here, we see how the property history is preserved in the Web application.

\section{Property}

\begin{tabular}{|l|lllllll}
\hline ID & Name & Date & Code & Origin & Union & Divison & Modified \\
\hline 497 & Serpins & 2020-09-24 00:00:00 & Ser1234567 & Serpins & None & None & Y \\
& & Complete Registration & Property History & Delete & Complete Visualization & Return \\
\hline & Beneficiary & Impacted & Destination & Litigation & Documents & ThirtyCM \\
\hline
\end{tabular}

Figure 6. Property “Serpins" (ID = 497).

The preservation of the property history remains in the Web application. In this example, we selected the property "Serpins", with the objective to create a new beneficiary for this property, so we select the Beneficiary button in Figure 6. This action redirects the user to a new page where we can see that property "Serpins" already as one beneficiary as shown in Figure 7. For adding a new beneficiary, we must fill a form as shown in Figure 8 and click in the "Add Beneficiary" button.

We need to create the history for every action that is done to this property (ID $=497$ ), having each version of this property stored in the database. When we edit a property, the history must be preserved, so we can have a "picture" of the property at any time. All the actions done in the Web application will continue the pursuit of creating a history for all properties stored in the database.

Therefore, after we create the new Beneficiary, it is not added to the table Beneficiary of the property "Serpins" with the ID $=497$. To create a history, we duplicate the property (ID $=497$ ) with all the information this property and add the new beneficiary to the duplicate. Figure 9 shows the duplicate created with the same name "Serpins" but with a new ID $=498$. In Figure 10, we can see that the duplicate has a new Beneficiary. When we duplicate the property to create a new one with newly added information, everything that the property has, like beneficiaries, destinations and other are copied to the duplicate and the new information is added. Thus, in this example, the property with the ID = 497 has one beneficiary, and when we created a new beneficiary, the Web application created a duplicate of the property 497 and add the new beneficiary in the duplicate. In the database, we have the version of the property (ID $=497$ ) with one beneficiary and the other version (ID $=498$ ) with two beneficiaries.

\section{Beneficiary}

\begin{tabular}{|c|c|c|c|c|c|c|c|c|c|c|c|c|c|}
\hline wqerqw & & & $\begin{array}{l}\text { Viana } \\
\text { do } \\
\text { Castelo }\end{array}$ & 1243412 & & & 1243 & $\begin{array}{l}2020-09- \\
03\end{array}$ & & $\begin{array}{l}\text { Property } \\
\text { Registration }\end{array}$ & Delete & Edit & $\begin{array}{c}\text { Manage } \\
\text { Documents }\end{array}$ \\
\hline
\end{tabular}

Figure 7. Beneficiary of the property "Serpins" (ID = 497). 


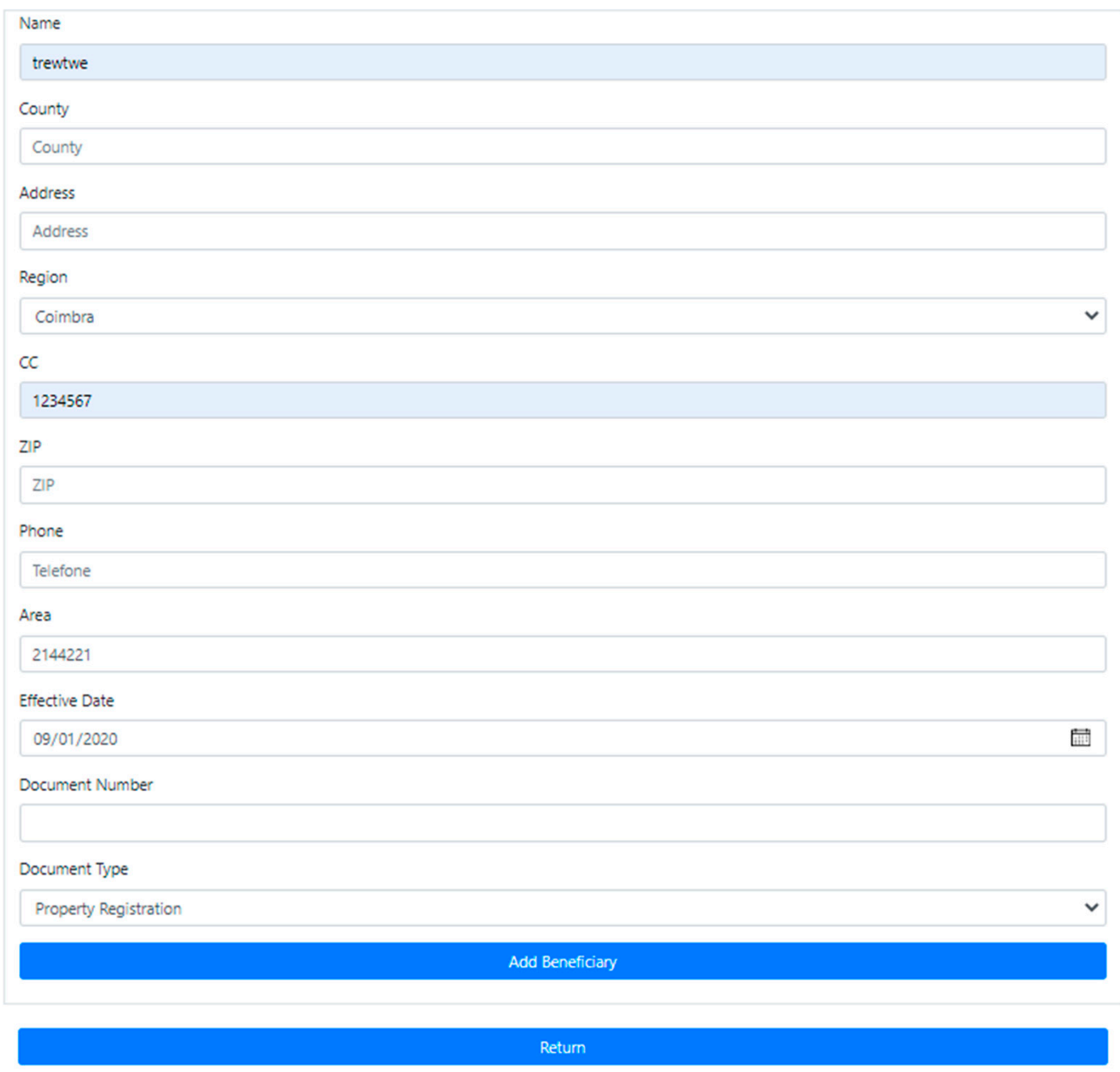

Figure 8. Beneficiary form for adding new beneficiaries.

\section{Property}

\begin{tabular}{|c|c|c|c|c|c|c|c|c|c|c|c|}
\hline ID & Name & \multicolumn{2}{|l|}{ Date } & \multicolumn{3}{|c|}{ Code } & Origin & \multicolumn{2}{|c|}{ Union } & Divison & Modified \\
\hline \multirow[t]{3}{*}{498} & Serpins & \multicolumn{3}{|l|}{$2020-09-2400: 00: 00$} & \multicolumn{2}{|l|}{ Ser1234567 } & Serpins & \multicolumn{2}{|c|}{ None } & None & Y \\
\hline & & Complete Regis & & & ty History & Delete & \multicolumn{3}{|c|}{ Complete Visualization } & \multicolumn{2}{|l|}{ Return } \\
\hline & & Beneficiary & & & Destination & Litiga & & & & & \\
\hline
\end{tabular}

Figure 9. Property “Serpins" (ID = 498). 


\section{Beneficiary}

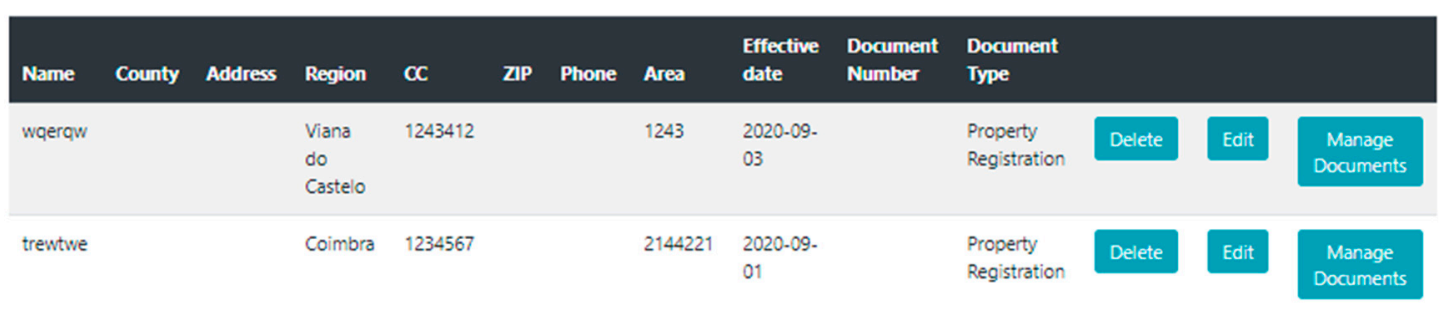

Figure 10. Beneficiaries of the property "Serpins" (ID = 498).

\section{Discussion}

When the properties are created in QGIS, they are automatically saved in the database that is linked to the Web application, which allows us to include more information in the properties.

The examples of the Web application show some of the aspects that the Web part contains, where site pages' follow the same basic principles. A table is visible ever it is possible to present the content to the user (Land Registry Specialist). If the user needs to add new content, he or she must fill in a form, and it is also possible to delete a property content. All data filled in the respective forms must be filled in by Land Registry Specialist to assure the veracity of the database.

The Web application allows actions such as associating inspections, complaints, intrusions, among others, to be associated with the respective properties, whether these are recent or properties that have already existed, but that no longer exist today. Although they do not exist, it is possible to associate information to them that may help in legal processes or just in market studies.

The proposal to the property history also deeply depends on the user's performance. In the example discussed in Section 3.2, union and division actions require the user to fill in many of the fields of the new created properties. In a division, the user must enter the same data found in the originated properties, and indicate the origin property that suffered division. This proposal requires the user to do all these steps correctly to maintain a history that corresponds to reality.

When there is an addition, the process is similar to a division, and all the history is preserved if the user will enter the correct data. These actions must be accomplished with the user responsibility of the user, retaining the desired quality of the database, but needs a minimum knowledge in the topic.

In order to preserve the property history solution in QGIS, the Web application must also create a history for all these actions. Every information that is included in a property, will create an automatic copy of the old property, and this new information is added to the copy property.

These properties modifications can be done in the Web application and in QGIS. Thus, we can edit all properties in the database, and the modifications are added to the property history. All actions create a history version of a property in the database.

The three components (Database, QGIS, and Web application) are interconnected materializing a support tool for land management. With QGIS, we create and edit properties, following the right steps to maintain the history of these properties, which are automatically saved in the database. After using QGIS, we can complete the information associated with the properties by going to the Web application and adding information to the properties, which supports the history. Everything the user does within the site will create a history, and the user will know the evolution of the property over time. These three interconnected components comprise a tool for better land management.

\section{Conclusions and Future Work}

In this work, we propose an approach that solves the property history problem keeping the historical data in the database. The proposed tool consists of three components: (i) the Web application, (ii) the database, and (iii) QGIS. These three modules form the solution to the property history problem. The database stores all the information created in the tool and QGIS allows the editing of properties, 
maintaining their history. In the Web application, it is possible to add information to the properties created in QGIS, while maintaining a history of all the actions made in the application for a specific property. The main contribution of this work is that, besides preserving the history of properties, it is possible to edit this history-that is, to edit properties that no longer exist today, but that the user wants to add information to, for legal reasons or other. This edition of properties history is innovative due to the fact it is not developed in other projects.

As future work, we intend to improve the Web application, such as the aesthetics of the Web application, making all Web pages responsive, adding security to the Web application, and improving the forms. In addition, we want to explore the QGIS tool in detail to make the tool even easier.

Author Contributions: Conceptualization, R.R.S., J.B.; Methodology, B.C., R.R.S.; Software, B.C.; Validation, B.C., R.R.S., J.B.; Formal analysis, B.C., R.R.S., J.B.; Investigation, B.C.; Resources, B.C.; Data curation, B.C.; Writing-original draft preparation, B.C.; Writing-review and editing, B.C., R.R.S., J.B.; Supervision, R.R.S., J.B.; Project administration, R.R.S., J.B.; Funding acquisition, J.B. All authors have read and agreed to the published version of the manuscript.

Funding: This research received no external funding.

Acknowledgments: We acknowledge Centre of Informatics and Systems of University of Coimbra (CISUC) for the facilities offered during this project.

Conflicts of Interest: The authors declare no conflict of interest.

\section{References}

1. Burja, V.; Tamas-Szora, A.; Dobra, I.B. Land Concentration, Land Grabbing and Sustainable Development of Agriculture in Romania. Sustainability 2020, 12, 2137. [CrossRef]

2. Beek, K.J. Land Evaluation (FAO Method) for Sustainable Land Use Planning and Management: Status and Perspectives; Latin American soil science cong: Aguas de Lindoia, Brazil, 1996.

3. Brumana, R.; Oreni, D.; Cuca, B.; Rampini, A.; Pepe, M. Open Access to Historical Information for Landscape Analysis in an SDI Framework. Int. J. Agric. Environ. Inf. Syst. 2013, 4, 18-40. [CrossRef]

4. Maretti, C. Grilagem de Terras na Amazônia-Negócio Bilionário Ameaça a Floresta e Populações Tradicionais. WWF-Brasil. Available online: https://www.wwf.org.br/natureza_brasileira/ reducao_de_impactos2/agricultura/agr_soja/agr_soja_problemas/agr_soja_problemas_erosao/\%0Ahttps: //www.wwf.org.br/wwf_brasil/ (accessed on 25 September 2020).

5. Liang, Y.; Sun, W.; Diao, H.; Li, Y. The Design and Development of the Land Management System in Dingzhuang Town Based on Spatial Data. In Proceedings of the Computer and Computing Technologies in Agriculture IV, Nanchang, China, 22-25 October 2010; pp. 57-65.

6. Barboda, C. Grileiro Continua Ocupando Terras da União e Ameaçando Famílias. Grilagem MT. 2020. Available online: https://diplomatique.org.br/grileiro-continua-ocupando-terras-da-uniao-e-ameacandofamilias/\#: \{\}:text=Grileiro\%20continua\%20ocupando $\% 20$ terras $\% 20$ da $\% 20$ Uni $\%$ C3\%A3o $\% 20$ e $\% 20$ amea $\%$ C3\%A7ando $\% 20$ fam $\%$ C3\%ADlias,-Grilagem $\% 20$ MT\%20\%7C\%20Brasil\&text=Mesmo\%20ap $\%$ C3\%B3s $\%$ 20decis $\%$ C3\%A3o \%20da\%20Justi $\%$ C3\%A7a,h\%C3\%A1\%20mais\%20de\%2015\%20anos (accessed on 17 November 2020).

7. Almeida, T.F. Invasões de Terrenos Públicos e a Responsabilidade do Poder Público. 2019. Available online: https://domtotal.com/noticia/1403983/2019/11/invasoes-de-terrenos-publicos-responsabilidade-do-poderpublico/ (accessed on 25 September 2020).

8. Araújo, R.M. Uma Retrospectiva da Expansão do Sistema Elétrico na Bacia do rio Tocantins, com Estudo de Caso na Região de Lajeado-Palmas_Porto Nacional (TO), 1996-2003. Master's Thesis, Universidade Estadual de Campinas, Campinas, Brazil, 2003.

9. Barbosa, E.; Lolis, S.; Pereira, C. Do rio Tocantins a UHE do Lajeado: A memória da população ribeirinha de Brejinho de Nazaré. Revista Interface 2015, 9, 191-203.

10. Prus, B.; Wilkosz-Mamcarczyk, M.; Salata, T. Landmarks as Cultural Heritage Assets Affecting the Distribution of Settlements in Rural Areas-An Analysis Based on LIDAR DTM, Digital Photographs, and Historical Maps. Remote Sens. 2020, 12, 1778. [CrossRef] 
11. Shirvani, Z.; Abdi, O.; Buchroithner, M.F. A Synergetic Analysis of Sentinel-1 and -2 for Mapping Historical Landslides Using Object-Oriented Random Forest in the Hyrcanian Forests. Remote Sens. 2019, 11, 2300. [CrossRef]

12. Seiler, U.; Schmidt, J.; Müller, R.; Müller, F. Forest Meadows-Relicts of a Historical Cultural Landscape in the Conservation Area of Saxon Switzerland? AGIT J. Angew. Geoinform. 2018, 4, 425-431.

13. Cecchini, C. From data to 3D digital archive: A GIS-BIM spatial database for the historical centre of Pavia (Italy). J. Inf. Technol. Constr. 2019, 24, 459-471.

14. Krleza, P.; Behaim, J.; Kranjec, I.; Jurkovic, M. Recreating Historical Landscapes: Implementation of Digital Technologies inArchaeology. Case Study of Rab, Croatia. In Proceedings of the 2018 International Conference on Intelligent Systems (IS), Funchal, Madeira, Portugal, 25-27 September 2018; Volume 24, pp. 132-139. [CrossRef]

15. Domingues, C.V.; Simões, L.L. O SIG na gestão pública: Análise crítica de um caso bem-sucedido-desafios e perspectivas. Exacta 2008, 5, 353-360. [CrossRef]

16. Ronen, Y. Illegal Occupation and Its Consequences. Isr. Law Rev. 2008, 41, 201-245. [CrossRef]

17. Bedderson, S.; Boshoff, K.; Botha, S.; Cyster, C.; Esterhuizen, L.; Gardener, D.; Kedzieja, M.; Lamohr, C.; Corlene Mostert, C.; Muller, A.; et al. Unlawful Occupation of Land-Cape Town. 2003. Available online: https://www.westerncape.gov.za/text/2005/7/notes_pie_acts.pdf (accessed on 14 November 2020).

18. OUP accepted manuscript. Eur. J. Int. Law 2020. [CrossRef]

19. Settlement of (Illegal) Occupation of National Non-Public Real Estates. Available online: https://www.fnp. gov.tw/fnpen/singlehtml/c2096b92dbdd415c9aef4c61fef0e655 (accessed on 14 November 2020).

20. Unlawful Occupation of Government Land. Available online: https://www.legco.gov.hk/yr11-12/english/ pac/reports/58/m_4b.pdf (accessed on 14 November 2020).

21. Mondal, S.; Chakravarty, D.; Bandyopadhyay, J.; Maiti, K.K. GIS based Land Information System using Cadastral model: A case study of Tirat and Chalbalpur rural region of Raniganj in Barddhaman district. Model. Earth Syst. Environ. 2016, 2. [CrossRef]

22. QGIS. Welcome to the QGIS project! Qgis. 2016. Available online: http://www.qgis.org/ (accessed on 25 September 2020).

23. Hurni, H. Assessing sustainable land management (SLM). Agric. Ecosyst. Environ. 2000, 81, 83-92. [CrossRef]

24. Pieri, C. Planning Sustainable Land Management: The Hierarchy of User Needs. Available online: http://wgbis. ces.iisc.ernet.in/energy/HC270799/LM/SUSLUP/KeySpeakers/APieri.pdf (accessed on 25 November 2020).

25. CDE. Sustainable Development Appraisal (SDA): A Methodological Tool for the Participatory Assessment of Sustainability from Local to Regional Planning Levels; Centre for Development and Environment (CDE): Berne, Switzerland, 2000.

26. Laskos, A.A.; Cazella, A.A.; Rebollar, P.B.M. O Sistema Nacional de Cadastro Rural: História, limitações atuais e perspectivas para a conservação ambiental e segurança fundiária. Desenvolv. e Meio Ambient. 2016, 36. [CrossRef]

27. Thomson, A.M.; Simpson, I. A grazing model for simulating the impact of historical land management decisions in sensitive landscapes: Model design and validation. Environ. Model. Softw. 2006, 21, 1096-1113. [CrossRef]

28. Da Victorino, S.P.; Amorim, A.; Shimabukuro, M.H. Share of information between Systems of Cadastre and Registry using a Cadastral Geographic Information System. Rev. Bras. Cartogr. 2015, 67, 1119-1130.

29. Amorim, A.; Malaman, C.S.; Sass, G.G. The modernization of Cadastral Update Processes and Temporal Analysis. Rev. Bras. Cartogr. 2013, 5, 375-382.

30. Francisco, H.R.; Imai, N.N. Temporalidade Em Sig: Aplicação Em Cadastro De Imóveis. Bol. Ciências Geodésicas 2009, 10, 89-104.

31. Toledo, B.H.C.; Bertotti, L.G. Brief history of certification of rural properties in Brazil and presentation of Landed Property Management System-SIGEF. Ambiência 2014, 10, 839-847. [CrossRef]

32. Freitas, C.F.S.; Lima, L.S. Cadastro Territorial e SIG no Processo de Regularização Fundiária: O caso das ZEIS do Planalto Pici em Fortaleza, Ceará. Available online: http://www.repositorio.ufc.br/bitstream/riufc/12308/ 1/2012_eve_cfsfreitas.pdf (accessed on 25 November 2020). 
33. De Melo, D.A.B.; Dias, S.; da Costa, S. Desenvolvimento de um SIGWEB Para a Gestão da Regularização Fundiária da Zona Rural do Município de Monteiro-PB. Available online: http://marte2.sid.inpe.br/col/dpi.inpe.br/marte2/2013/05.29.00.21.16/doc/p1057.pdf?metadatarepository= \&mirror=dpi.inpe.br/marte2/2013/05.17.15.03.08 (accessed on 25 November 2020).

34. Mishra, P.K.; Rai, A.; Rai, S.C. Land use and land cover change detection using geospatial techniques in the Sikkim Himalaya, India. Egypt. J. Remote Sens. Space Sci. 2020, 23, 133-143. [CrossRef]

35. Leaflet. Leaflet-A JavaScript Library for Interactive Maps. Available online: http://leafletjs.com/ (accessed on 25 September 2020).

36. WHO/HQ/WHE/HIM/MAP (GIS team). Comparison of Geographic Information Systems (GIS) Software. Available online: https://www.who.int/health-cluster/resources/publications/OpenSourceGISComparison. pdf (accessed on 25 November 2020).

37. Esri. ArcGIS Online. 2014. Available online: https://www.arcgis.com/index.html (accessed on 25 September 2020).

38. GvSIG. Inicio-Portal gvSIG. 2009. Available online: http://www.gvsig.com/es/inicio (accessed on 25 September 2020).

39. Google Earth Pro. Available online: https://www.google.com/intl/pt-PT_ALL/earth/ (accessed on 25 September 2020).

40. Esri, What Is Archiving-ArcGIS Pro|Documentation. Available online: https://pro.arcgis.com/en/pro-app/ help/data/geodatabases/overview/what-is-archiving-.htm (accessed on 25 September 2020).

Publisher's Note: MDPI stays neutral with regard to jurisdictional claims in published maps and institutional affiliations.

(C) 2020 by the authors. Licensee MDPI, Basel, Switzerland. This article is an open access article distributed under the terms and conditions of the Creative Commons Attribution (CC BY) license (http://creativecommons.org/licenses/by/4.0/). 